\title{
'Outside the industry, nobody knows what we do' SEO as seen by search engine optimizers and content providers
}

\author{
Sebastian Schultheiß ${ }^{1}$ and Dirk Lewandowski ${ }^{2}$ \\ ${ }^{1}$ Hamburg University of Applied Sciences, Germany; sebastian.schultheiss@haw-hamburg.de \\ ${ }^{2}$ Hamburg University of Applied Sciences, Germany; dirk.lewandowski@haw-hamburg.de \\ This is a preprint of an article accepted for publication in Journal of Documentation \\ http://dx.doi.org/10.1108/JD-07-2020-0127
}

\begin{abstract}
- Purpose: In commercial web search engine results rankings, four stakeholder groups are involved: search engine providers, users, content providers, and search engine optimizers. Search engine optimization (SEO) is a multi-billion-dollar industry and responsible for making content visible through search engines. Despite this importance, little is known about its role in the interaction of the stakeholder groups.

- Design/methodology/approach: We conducted expert interviews with 15 German search engine optimizers and content providers, the latter represented by content managers and online journalists. The interviewees were asked about their perspectives on SEO and how they assess the views of users about SEO.

- Findings: SEO was considered necessary for content providers to ensure visibility, which is why dependencies between both stakeholder groups have evolved. Despite its importance, SEO was seen as largely unknown to users. Therefore, it is assumed that users cannot realistically assess the impact SEO has, and that user opinions about SEO depend heavily on their knowledge of the topic.

- Originality: This study investigated search engine optimization from the perspective of those involved in the optimization business: content providers, online journalists and search engine optimization professionals. The study therefore contributes to a more nuanced view on and a deeper understanding of the SEO domain.
\end{abstract}

Keywords: search engine, search engine optimization, SEO, interview, expert interview, search engine optimizer, content provider, online journalist, search engine user

\section{Introduction}

Search engines play an important role in our society. They are among the most widely used services on the internet (Purcell et al., 2012), which gives them tremendous influence on the knowledge acquisition of internet users. The search engine market is dominated by Google, which possessed a market share of $89 \%$ in the US (StatCounter, 2019) and 94\% in Europe (StatCounter, 2020) across all platforms as of December, 2019.

Google and other commercial search engines generate revenue mainly through search-based advertising (sponsored links). In 2018, 83\% of Google's annual revenue of $\$ 136.8$ billion was generated by advertising (Alphabet Inc., 2019). This revenue allows Google to invest billions in research, allowing the company to continue refining its ranking algorithms (Alphabet Inc., 2017). However, search engine operators are not the only ones involved in determining rankings. According to Röhle (2010, p. 80), three additional stakeholder groups participate in search engine rankings: search engine optimizers, content providers, and users. 
Search engine optimization (SEO) is 'the practice of optimizing web pages in a way that improves their ranking in the organic search results' (Kai Li et al., 2014, p. 3110). SEO is part of Search Engine Marketing (SEM). Besides SEO, SEM also includes paid search marketing (PSM), which refers to keyword-related advertisements (Kai Li et al., 2014). In 2020, SEO revenue is expected to reach $\$ 80$ billion in the U.S. alone (McCue, 2018). Content providers such as online shops and media outlets acquire a significant proportion of their traffic from search, especially via Google. The percentage of all page impressions coming from search is between $20-30 \%$ for journalistic content (e.g., nytimes.com (30\%), washingtonpost.com (33\%), and Germany's zeit.de (23\%); see similarweb.com, 2020). SEO is also relevant for other forms of content, such as scientific articles (academic SEO; see Beel et al., 2010). Hence, it can be concluded that both groups, the search engine optimizers and content providers, are highly sophisticated and depend heavily on search engines.

The stakeholder groups of search engine providers, content providers, and search engine optimizers are faced with users who have a high level of trust in search engines and in Google in particular. This has been demonstrated by numerous studies for instance on the trustworthiness of search results (Purcell et al., 2012), on trust in results rankings (Pan et al., 2007; Schultheiß et al., 2018), and on the use of search engine rankings as a criterion for the quality of content (Westerwick, 2013). In addition to the great trust that users place in search engines, there is also a lack of knowledge about how they function and where their revenue comes from. Through group discussions and a quantitative survey, Stark et al. (2014) found that users have little knowledge of how search engines rank results. The participants also had difficulties formulating precise search queries. A representative survey by Lewandowski et al. (2018) showed that German Internet users are not sufficiently familiar with Google's business model and have difficulties distinguishing ads from organic results. However, most subjects rated their own searching skills as 'good' or 'very good.' This disparity between self-assessed and measured skills was also revealed by the Singer et al. (2012) study. Three quarters of participants stated that they had found the solution to a complex search task, but this was only true for every second subject. We can therefore assume an imbalance of power between the stakeholder groups to the disadvantage of users.

This paper presents interviews with 15 German search engine optimizers and content providers, the latter represented by content managers and online journalists. The interviews were conducted as part of the SEO-Effekt ${ }^{[1]}$ (SEO Effect) project, which has the goal of describing and explaining the role of SEO from the perspectives of the participating stakeholder groups. The expert interviews were conducted at the beginning of the project and had two main objectives. First, we sought to gain an understanding of search engine optimization from the perspective of the stakeholder groups responsible for providing content and making it visible through search engines. Second, we obtained expert assessments on search engine user perspectives regarding SEO to generate hypotheses for future project phases.

The rest of the paper is structured as follows. First, we will provide an overview of studies on the perspectives of the stakeholder groups regarding the influence they have on search engine ranking. Then, we will describe the methods used in the expert interviews. Next, we will present the results in four parts: professional background of the interviewees, the effect of SEO from the interviewee perspective, user perspectives on SEO, and factors influencing user perspectives on SEO. Finally, we discuss the results, provide a summary, and present suggestions for future research.

\section{Stakeholder groups and their influence on search results}

Search engines are a key service of the internet. They are an essential tool that enables users to navigate the web (Machill et al., 2008, p. 591; Tavani, 2012; Varian, 2006, p. 177). Usually, search engines are regarded as neutral intermediaries that rank results objectively. Thus, each document in the index would be treated according to the same criteria and would have the same chance of being shown at a certain position for a specific query. 
As explained in the introduction, users trust Google and other services to provide them with the 'right' results to their query. Following this model, all factors that are contrary to such an objective ranking can be regarded as deviations ('Search Engine Bias', see Tavani, 2012). However, it can be argued that search engines generate bias through their rankings per se (Grimmelmann, 2010; Lewandowski, 2017). In addition, search engines can no longer be regarded as neutral information intermediaries due to two circumstances. Firstly, search engine providers themselves have become content providers who have an interest in their own content being shown prominently (see antitrust case on Google Shopping, European Commission, 2017). Secondly, search engine companies do not determine the ranking of results single-handedly. According to Röhle (2010, p. 80), three further stakeholder groups are involved in search engine rankings: content providers, search engine optimizers, and users, as illustrated in figure 1.

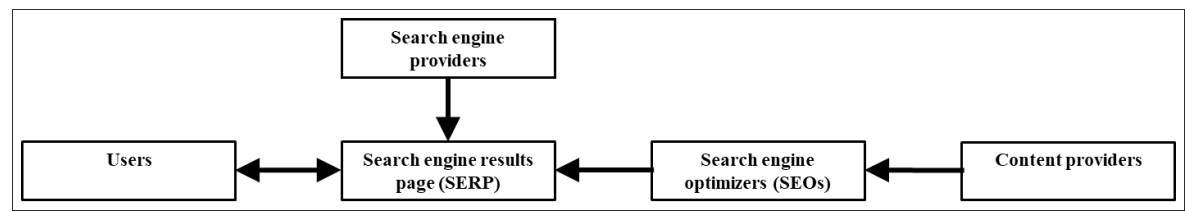

Figure 1: Stakeholder groups (adapted and translated from Röhle, 2010, p. 80)

Röhle (2010, p. 80) refers to the Actor-Network Theory of Latour (2005), according to which search engines can be interpreted as associations of human and non-human actors (Rieder, 2005). The individual actors come together in stakeholder groups. They are characterised by their common direction of movement, which Latour (1990) labels a program of action. Google's program of action, which is 'to organize the world's information and make it universally accessible and useful' (Google.com, 2020), is very similar to that of the users: to retrieve information as inexpensively and quickly as possible. In contrast, there are the content providers who, through their individual striving for attention, pursue a different program of action than Google. The stakeholder group of search engine optimizers is directly associated with the content providers and also works towards increased attention for specific pieces of content (Röhle, 2010, p. 81).

In the following, the stakeholder groups and their perspectives on ranking will be discussed in greater detail.

\section{The search engine provider perspective on ranking}

Search engine provider perspectives on the creation of rankings have been investigated previously. Van Couvering (2007) conducted interviews with search engine operators about their definition of quality. She identified two ways in which the interviewees perceived quality, namely market and science/technology driven. She concluded that this approach leaves little room for questions about public welfare, fairness or bias. Mager (2012) conducted interviews with stakeholders involved in the development of search engines. The results indicate that the search engines and their business models are stabilized by the involved stakeholder groups. The users are willing to provide their data in exchange for the services of the search engines. The website providers, in turn, are forced to design their pages according to the search algorithms in order to gain visibility. Mager (2012) therefore proposes to examine not only the effects of search engines on society, but also the balance of power between the involved stakeholders. In another study, Mager (2018) interviewed key players from the public sector, the legal community, civil society, and the IT industry, including a Google employee, on the topic of Internet governance (IG). Google was perceived as a powerful actor that privately executes tasks and responsibilities which are of public interest. This influence of the algorithms (governance by algorithms) was associated by the interviewees with various regulatory proposals (governance of algorithms). Mager (2018) concludes that joint efforts are needed to achieve a redistribution of power that challenges central actors such as Google and the dominant roles they play. 
Regarding the question of whether search engine users prefer organic results or ads, Neethling (2007) conducted a user survey and interviews with search engine employees. The interviews showed that search engine employees assumed a preference for sponsored results by the users. In contrast, the users considered organic results to be slightly more relevant, confirming the results of a previous study by Jansen and Molina (2006).

Since we could not identify studies dealing with the user's perspective on SEO, in the following literature review, we focus on search engine optimizers, content providers and the interdependencies of these two stakeholder groups.

\section{Search engine optimizers, content providers and their interdependencies}

SEO aims to optimize websites so that they meet the ranking criteria of search engines such as Google. However, neither a complete list of criteria nor their weightings are published by the search engines. Information about which factors are relevant for SEO is provided by books for professionals (e.g., Clarke, 2019; Erlhofer, 2018), which appear regularly in updated editions, or by websites (e.g., Moz.com, 2020; searchengineland.com, 2020), which provide up-to-date information about new developments in the SEO industry.

Several studies seek to shed light on the significance of the individual factors. Some of these studies investigate the correlations between specific SEO techniques and result rankings (e.g., Giomelakis and Veglis, 2016; Moz.com, 2015; Ziakis et al., 2019). Others use interviews and questionnaires to gather information from SEO experts. Most of these studies deal with techniques which are regarded as beneficial to website rankings. Such techniques include on-page factors including optimized meta tags and page speed optimization as well as off-page factors such as the number of backlinks (Akram et al., 2010; Niranjika and Samarasighe, 2019; Sheffield, 2020; Zhang et al., 2011). Other interviews with search engine optimizers focus on the objectives and metrics of SEO (Rashid et al., 2018) as well as on unethical black hat SEO techniques (Zuze and Weideman, 2013). Black hat SEO involves techniques that are considered illegal by most search engines and are generally penalized with a lower ranking when discovered, such as white text on a white background. Consequently, SEO can pursue both positive and negative goals. On the one hand, SEO can be practiced as a legitimate improvement in the sense of making a website better indexable for search engines and easier to find. On the other hand, there are unethical black hat SEO techniques. Drawing on materials from ethnographic fieldwork with search engine optimizers in the United Kingdom, Ziewitz (2019) examined the ethicality of optimization. He found that the search engine optimizers in his study were constantly renegotiating between 'good' and 'bad' SEO measures, with these negotiations representing a significant part of their daily work.

Similar to the studies that draw on SEO experts, studies with content providers also examine SEO techniques for their relevance, but in the context of journalistic content instead. Thus, Lopezosa et al. (2019) compared the SEO performance of a number of digital newspapers in Spain and Giomelakis and Veglis (2016) found correlations between SEO techniques and the traffic experienced by popular Greek news websites.

However, the aforementioned correlation studies as well as the interviews and questionnaires only cover SEO techniques that were considered to be relevant at the time of the study. Thus, they do not provide information about the actual impact of SEO on the results of commercial search engines.

Further studies, also in the form of interviews, provide a more in-depth examination of the search engine optimizers' perspectives on their work and their interaction with content providers. The work of Dick (2011) focuses on the impact that SEO can have on the way journalists work. He conducted interviews with SEO practitioners working for UK news media. Although SEO played a role in the media organisations at that time, there were reservations about SEO possibly imposing restrictions on journalistic work. Similar reservations were expressed by SEO representatives of Greek (Giomelakis et al., 2019) and Indonesian (Prawira and Rizkiansyah, 2018) newsrooms. According to the interviewees of Giomelakis et al. (2019), SEO was considered indispensable as it ensures visibility of 
the content. However, it was emphasized that SEO has a major influence on topic setting and that this can reduce the quality of the journalism being produced. Likewise, the journalists interviewed by Prawira and Rizkiansyah (2018) expressed serious reservations towards SEO, maintaining that SEO would violate journalistic ethics. A study by Van Couvering (2009, p. 181-204) considers search engine marketers (PSM and SEO). She investigated the extent to which there are dependencies between marketers and the search engines. She concluded that both parties are directly dependent on one another and work together to maximize their profits.

\section{Method: expert interviews}

The expert interviews were conducted with 15 persons, five from each of the following three groups, with the latter two representing the content provider stakeholder group.

Search engine optimizers working on behalf of content providers

Content managers at content providers who have hired search engine optimizers or employ them at their own companies

Online journalists who have had exposure to SEO as part of their professional activities, for instance in the form of SEO courses designed for journalists

The experts, for example freelance journalists, were recruited via our contact network (3 interviewees) and via publicly accessible profiles and homepages (12 interviewees). We contacted 5 search engine optimizers, 37 content managers, and 15 online journalists directly.

The interviews took place between July and August 2019 after a successful pre-test with a search engine optimizer from a German online marketing company. Individual appointments were made in the respondents' offices $(n=6)$ or for a Skype call $(n=9)$, depending on the interviewee's location. 12 of the interviewees were men, three were women. Before the interview began, the interviewees signed a declaration of consent, which included the option to agree to the upload of pseudonymized transcripts to a research data management repository. The average duration of the interviews, excluding introductory and closing phases, was 33:48 minutes ( $\mathrm{SD}=$ 9:08 minutes). The conversations were recorded with a voice recorder (Olympus LS-11 ${ }^{[2]}$ ) or using the Skype software. At the end of each interview, a small gift was presented to the interviewee or sent in the mail.

\subsection{Research questions}

Since the interviews were aimed at understanding the experts' perspectives on SEO (RQ1, RQ2) and their assessments of user perspectives on SEO (RQ3), our research questions were as follows:

RQ1: What motivates search engine optimizers to work in the field of SEO and how do they assess the SEO impact?

RQ2: How does SEO affect the daily work of content managers and online journalists?

RQ3: How do search engine optimizers, content managers and online journalists assess users' perspectives regarding SEO?

\subsection{Interview guideline}

The interview guideline consists of four blocks, which refer to the above-mentioned research questions. The questions of Block I were designed to learn more about the professional background of the experts and their assessments of SEO influence (RQ1). Block II was discussed with all three 
groups and refers to RQ3. Block III, which targets RQ2, was only addressed to the content managers and online journalists. To ensure a smooth conclusion of the interviews, the search engine optimizers were asked about their motivation to work in the SEO industry (RQ1) at the end of the interview. Table I lists the interview questions, with the column 'interview group' indicating differences in the guidelines. The interviews were conducted in German.

Table I: Interview guideline

\begin{tabular}{|c|c|c|}
\hline No. & Interview question (translated from German) & $\begin{array}{l}\text { Interview } \\
\text { group }\end{array}$ \\
\hline \multicolumn{3}{|c|}{ I. Self-description and assessment of the SEO influence } \\
\hline 1.1 & $\begin{array}{l}\text { At the beginning of the interview, would you please briefly describe your role in the } \\
\text { company and how long you have been active in the field of SEO? }\end{array}$ & SEO \\
\hline 1.2 & $\begin{array}{l}\text { At the beginning of the interview, would you please briefly describe your role in the } \\
\text { company and the points of contact you have with SEO in your everyday work? }\end{array}$ & $\begin{array}{l}\text { Content } \\
\text { managers/ } \\
\text { Online } \\
\text { journalists }\end{array}$ \\
\hline 1.3 & $\begin{array}{l}\text { Before we start talking about the users: From your point of view, what influence does } \\
\text { SEO have on the search results? }\end{array}$ & all \\
\hline \multicolumn{3}{|c|}{ II. Users' perspectives regarding SEO } \\
\hline 2.1 & $\begin{array}{l}\text { If you think of the German search engine users: How do you assess the user } \\
\text { knowledge about the fact that SEO can influence the search results? }\end{array}$ & all \\
\hline 2.2 & $\begin{array}{l}\text { Now, if we look at those users who know about SEO: In your opinion, how influential } \\
\text { do users think SEO can be on search results? }\end{array}$ & all \\
\hline 2.3 & $\begin{array}{l}\text { What do users, in your opinion, think about the SEO influence on search results? } \\
\text { Would you consider the opinion as positive or negative? }\end{array}$ & all \\
\hline 2.4 & $\begin{array}{l}\text { If we now take a closer look at the various user groups: In your opinion, are there } \\
\text { differences in the user's view of SEO if, for example, different age groups or } \\
\text { educational levels were compared? If so, how do you rate these differences? }\end{array}$ & all \\
\hline \multicolumn{3}{|c|}{ III. Impact of SEO on daily work } \\
\hline 3.1 & $\begin{array}{l}\text { At the beginning of the interview we already talked about connecting points between } \\
\text { your work and SEO. How would you describe the importance of SEO in your daily } \\
\text { work? }\end{array}$ & \multirow{2}{*}{$\begin{array}{l}\text { Content } \\
\text { managers/ } \\
\text { Online } \\
\text { journalists }\end{array}$} \\
\hline 3.2 & $\begin{array}{l}\text { When you look to the future: In your opinion, how will the relationship between } \\
\text { content managers/journalism and SEO change in the future? }\end{array}$ & \\
\hline \multicolumn{3}{|c|}{ IV. Closing question } \\
\hline 4. & $\begin{array}{l}\text { Finally, a question about your personal view of your work: What is your main } \\
\text { motivation to work as a search engine optimizer? }\end{array}$ & SEO \\
\hline
\end{tabular}

\subsection{Qualitative content analysis}

To analyse the interviews, we first prepared the data, defined the unit of analysis, and developed the coding scheme, as described by Zhang and Wildemuth (2009) for qualitative content analysis (QCA) in general. Next, we applied consensus coding as specified by Richards and Hemphill (2018), using version 10 of the MAXQDA ${ }^{[3]}$ software.

We prepared the data by transcribing the audio recordings and pseudonymizing the transcripts, which we later made available (see section Research data). Then, we defined the unit of analysis as complete sentences to be assigned to a respective code. Exceptions were sentences in which the interviewee spoke of a number of different aspects. In these cases, only the corresponding phrases were coded. Next, we developed categories using a mixed approach. We deductively developed the 
main categories based on the interview guideline, before inductively creating the final coding scheme based on a sample of six randomly selected transcripts.

The consensus coding was carried out by a project employee and a student assistant. To achieve a conformity in coding and to check the comprehensibility of the category system and its descriptions, we first calculated the intercoder reliability for training purposes using a sample of three randomly selected transcripts. Both coders agreed in $89 \%$ of the assigned codes. Examples of disagreements are text passages that were coded by one of the coders but not the other, or passages that were interpreted differently, e.g., on the assumed user knowledge of SEO. Afterwards, since specifications of the category system did not appear to be necessary, all transcripts were coded by both coders independently using the final coding system (see Appendix 1). These two sets of 15 documents each were then compared, disagreements discussed, and a uniform coding agreed upon.

\section{Results}

Of the search engine optimizers, three were founders and CEOs of SEO agencies, two others were employees at media organizations. The content providers were responsible for platforms ranging from lifestyle, automotive, web agency, tourism and journalism. The online journalists were either employed by a broadcasting company or a publishing house, or they were freelancers. Table II presents the experts in greater detail.

Table II: Professional background of the interviewees

\begin{tabular}{|c|c|c|c|}
\hline & ID & Role at company/Professional background & Company \\
\hline \multirow{5}{*}{ 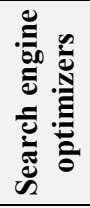 } & S01 & Founder and CEO & SEO agency (since 2013) \\
\hline & S02 & Founder and CEO & SEO agency (since 2006) \\
\hline & S03 & Deputy Head of Audience Development & National newspaper (since 2010) \\
\hline & S04 & Founder and CEO & SEO agency (since 2008) \\
\hline & S05 & Head of SEO & Publisher (since 2012) \\
\hline \multirow{5}{*}{ 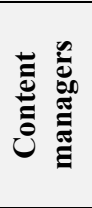 } & $\mathbf{I 0 1}$ & CEO and owner & Lifestyle magazine \\
\hline & I02 & Head of Digital Experience Marketing & Automobile manufacturer \\
\hline & I03 & Shareholder and CEO & Web agency \\
\hline & I04 & Owner & Tourism website \\
\hline & $\mathbf{1 0 5}$ & Portal manager online presence & Regional daily newspaper \\
\hline \multirow{5}{*}{ 兽 } & $\mathbf{J 0 1}$ & Online journalist & Broadcasting company \\
\hline & $\mathbf{J 0 2}$ & Online journalist & Small publisher \\
\hline & $\mathbf{J 0 3}$ & Editorial manager & Online platform/magazine \\
\hline & J04 & Journalist, print and digital & Freelancer \\
\hline & $\mathbf{J 0 5}$ & Freelancer & Broadcasting company \\
\hline
\end{tabular}

\subsection{Search engine optimizers' reflections on their work}

Most search engine optimizers described their motivation to work in the field of SEO as technically driven. A deep interest in Google's functionality and societal significance (S01), in the ongoing developments in the search engine sector (S03 and S05), as well as a fascination with Google's complexity (S04) were crucial for their personal career decisions. In addition to the technical component, respondents expressed the need to create value for search engine users to find what they are looking for. With a wink, interviewee S02 described SEO as 'a good job that makes the world a little better'. Another search engine optimizer described his motivation quite similarly:

As a service provider, you try to make the internet a little bit better every day, which means that you 'push' the bad results to the lower ranks. And if the bad results come from your clients, you try to get the clients to 
produce better results. You also try to do your part so that the search engine user feels more secure and has more fun. This is of course an idealized picture, admittedly. But that is what the motivation behind it is. (S04)

From the point of view of two search engine optimizers, their industry has a significant influence on search results. According to S01, 'nothing works if you don't draw attention to your site'. In addition, SEO is no longer expert knowledge, but a standard method, so that there are hardly any websites left that do not engage in SEO, as reported by S03. The other three search engine optimizers describe the influence of SEO in a more nuanced way. The influence is considered to be indirect and strongly related to the competition in which the website is operated. Thus, the SEO influence is considerably higher if the website is in a competitive field, as stated by S04. The search engine optimizers S02 and S05 emphasize that nowadays SEO focuses very much on improving the quality of the whole website, is strongly connected to other areas of website maintenance, and therefore the influence of SEO alone can hardly be determined.

SEO measures no longer have the goal of achieving maximum traffic at the expense of search result quality as in the past. Instead, the whole industry is moving in the direction of quality. (S02)

\subsection{SEO in the everyday lives of content providers}

When asked about the points of contact with SEO, all content managers (I01-I05) stated that they perform an interface function between their own institution and its employees as well as the SEO agency responsible for optimizing their content. In addition, three of the content managers stated that the key factor for their cooperation with an SEO agency was that organic traffic was considered to be crucial for the visibility of their content (I01, I02, I04).

Besides the points of contact with SEO, the content managers were also asked about the importance of SEO in their daily work. The significance of SEO is mainly reflected in the importance of the topic and less in the time required. The respondents I04 and I05 stated that the time SEO requires is low, but it is nevertheless an essential part of everything they do and something they always keep in mind when working:

The [SEO measures] are just standard things that we keep in mind. When I create a website, I never do it without an HTML head section where I define a title and a meta description including keywords. Since the systems we use to publish articles already take care of all that [...], we are not as aware anymore that we are doing things especially for SEO purposes. (I05)

The employee of the automobile manufacturer (I02) also stated that SEO currently is rather routine work, and that building up the SEO team a few years ago was the real challenge. The other two content managers rate the importance as even higher. The head of the web agency (I03) explicitly stated that the importance of SEO is high since SEO must always be considered when creating websites for clients. For the owner of the lifestyle magazine (I01), the importance of SEO creates additional challenges regarding the knowledge the magazine requires of its employees:

It [SEO] is always a big issue. We have different levels of knowledge in the editorial department. Some of our editors started out working in print. And of course, they must receive additional training. (I01)

As the answers to the question about the point of contact to SEO show, there was a certain necessity for the online journalists to address SEO topics. Thus, SEO is described as an essential tool to reach readers. Three of the five journalists have completed SEO training courses (J02, J03, J04) or acquired SEO knowledge on their own (J05) and are now passing on this knowledge to their journalist colleagues through courses and consulting (J03, J05). It is also emphasized that especially as a freelance journalist, SEO knowledge is necessary in order to continue to receive assignments (J04). In addition to this perceived job-related necessity, personal interest was also decisive for dealing with SEO topics (J01, J05). However, the described relevance of the topic is not yet strongly noticeable in everyday professional life. SEO is more in the background behind content quality (J03), is in the process of being established (J02), is not sufficiently addressed by the employer (J01) or is not a 
component of the current areas of responsibility (J05). Only one freelance journalist (J04) states that SEO has become an integral part of her work as her clients require this knowledge.

According to four of the five interviewed content managers, the relationship between content providers and SEO will change. Both fields will grow even closer together, as the battle for the top positions on the search engine results pages will become more intense (I01, I04). And even if SEO is often routine work, an immediate reaction is always required when Google changes its ranking algorithms:

I think that SEO is more and more relevant to anyone looking for information online. The battle for the first three positions will increase and so will SEO. SEO will also become faster because Google is going to change its parameters more frequently, so those who want to be ahead have to react quicker. (I04)

It is also assumed that the trend of content quality increasingly replacing classic SEO techniques (I03) will continue. In contrast, one content manager does not expect any major changes. He claimed that although anyone can take on the role of a content provider nowadays, many of them would not consider SEO (I05).

Regarding the expected changes in the relationship between SEO and journalism, content quality plays the most important role. For example, Google is expected to increasingly recognize which texts are of high quality, which is why good journalism is a prerequisite for all SEO activities (J01, J02). SEO must not take place 'at any price', but should rather act in the background (J03, J05). One freelance journalist (J04) fears the increased use of SEO-compliant writing. This could lead to a strong shift of attention, for example towards products, which would endanger neutral reporting.

The importance of SEO will increase, obviously, but you still have to provide people with relevant content, otherwise they will feel fooled. (J02)

Similar to the search engine optimizers, the content managers also described SEO as a standard method to generate visibility (I03, I05), with I05 mentioning the constraint that offering unique content must always come first. The other three content managers also share this view of a high SEO influence (I01, I02, I04). The fact that SEO provides visibility would have made it possible for the SEO industry to become as large as it is today, according to I01. In his opinion, this also created dependencies between SEO and content providers. In addition, I04 emphasizes that the importance of SEO is also due to the fact that it is the only way to 'get from page two to the top of page one', which he calls 'last-20-percent-optimization'.

Like the other two interview groups, the majority of journalists described the influence of SEO as very large. Without SEO, it is nearly impossible to achieve high visibility for content, as said by J01, since users only look at the top results (J04). Without SEO, Google would also be unable to adequately assess the relevance of the websites, according to J02. As already described by search engine optimizer S04, journalist J05 added that the importance of SEO is particularly great 'if you are not the market leader for a particular topic anyway'. One of the five online journalists (J03) stated that she simply could not assess the influence of SEO but hoped that it was 'not so strong'. She argues that SEO always means an adaptation to Google's ranking criteria, which must be viewed critically due to their market leadership. In courses in which she passes on her SEO knowledge to colleagues from online journalism, she therefore tries to focus more on quality factors such as the readability of the texts and the user experience of the website.

\subsection{User perspectives on SEO}

The respondents almost unanimously expect hardly any user knowledge about SEO. 14 of the 15 interviewees described the knowledge as very low or non-existent. S01 and I02 suspected that Paid Search Marketing (PSM) is probably known to users, while SEO is not. S05 explained the presumed lack of SEO knowledge by stating that the required SEO activities behind certain features are unknown. Users would associate services such as cooking recipes embedded on the SERP only with Google, but not with SEO. According to I05, user knowledge is absent because SEO activities are 
usually not communicated by content providers. Only one online journalist assumed that search engine users were familiar with SEO. However, they would also not know how the optimization works. She said:

I believe that the users know that there is SEO and that they get optimized results. But I think that the majority of users have no idea how SEO works, not even on a rudimentary level. (J01)

According to the respondents, there is both an over- and underestimation of the influence of SEO. These two positions are directly linked to the level of knowledge regarding SEO. Six interviewees (S01, S03, S05, I02, J02, J05) assumed that the few users who know SEO tend to overestimate the SEO influence. According to S05, some colleagues contact him as Head of SEO with the attitude that 'if you contact us then we will push it to the first position'.

By contrast, if little or nothing is known about SEO, six interviewees (S04, I01, I04, I05, J01, J04) assumed that the SEO influence is considered low by search engine users. This would be due to the fact that, in contrast to ads, there is no labelling for SEO (I01), well-implemented SEO measures are barely noticeable (I05), and users generally do not think about SEO (I04, J01, J04).

The other interviewees suspected a mixture of the two positions presented (over- and underestimation of the influence of SEO). A journalist pointed out that it is difficult even for SEO agencies to determine the direct impact of SEO measures:

Some effects cannot be clearly assigned to SEO. And many of these are correlations and not causalities. That's why I find it difficult to say 'SEO has exactly this particular effect'. (J03)

User opinions regarding SEO influence were more nuanced on the whole. Ten of the respondents, including all search engine optimizers as well as I04, I04, J01, J03 and J05, stated on the one hand that SEO could be perceived as manipulative if the level of knowledge about SEO is too low. Negative attitudes towards SEO could also have been caused by black-hat SEO measures used in the past, which resulted in users being confronted with irrelevant content (S03, S04) in some cases. On the other hand, if the level of knowledge about SEO grows, user opinions about SEO also improve according to the respondents, as the users would then reward the fact that relevant results are ranked first through SEO.

User opinion was assessed as positive by the content managers I01, I02, and I03. According to them, there would be no reason from the users' point of view to reject SEO, since the user would benefit directly from SEO and the quality of results would increase.

Opposite to this are the online journalists $\mathrm{J} 02$ and J04, who assumed a negative attitude of the users towards the SEO influence due to what is regarded as a manipulative intervention by SEO.

\subsection{Factors influencing user perspectives on SEO}

Regarding the question of whether the user's view of SEO might differ between different user groups, the factors of industry, educational level, self-interest, and age were discussed by the interviewees. Eight of the 15 respondents named the background of a search engine user as decisive for his or her view of SEO (S03, S04, I01, I03, J01, J02, J03, J04):

Anyone who has anything to do with marketing or sales or anything like that is of course closer to the topic of SEO. (I03)

In addition to a higher assumed SEO knowledge, one respondent (S03) also expected a more positive opinion of SEO among persons working in online marketing. He explained that people who are professionally involved with websites take a constructive approach and analyse their potential for improvement. If this professional approach is not given, the view on SEO is rather negative due to the various opportunities for manipulation.

Five interviewees rated the knowledge of SEO as higher among people with a high level of education (I01, I03, J02, J03, J05). One interviewee suspected a stronger questioning of the ranking among persons with a higher level of education (S04). Only from the point of view of respondent I02, the educational level is not a distinguishing factor of users' perspectives regarding SEO. Four 
interviewees stated that the SEO knowledge of some users can be justified by the users' personal interest in search engines (S01, I01, I02, I03).

Regarding the factor 'age', the results are divided. Seven respondents suspected that younger people were better informed about SEO (S05, I01, I03, I04, I05, J01, J02). In contrast, six respondents did not assume any differences in the users' view of SEO regarding their age (S01, S02, I02, J03, J04, J05):

I do not think that young people are more into it. They just use the internet and think even less about it [than older people]. (S02)

\section{Discussion}

From the statements of the search engine optimizers, it became clear that SEO is not (or no longer) understood as an optional method, but as a necessary standard activity for any website that seeks to achieve visibility. However, it is difficult to clearly distinguish SEO from other website maintenance activities, as SEO now involves improving the overall quality of the website. Due to these large overlaps, it is nearly impossible to ascertain the direct influence of SEO from the point of view of the respondents. The need to implement SEO measures was also emphasised by content managers and online journalists. The content managers with in-house search engine optimizers or commissioned agencies are expected to work even more closely with search engine optimizers in the future, as the battle for top rankings will increase. Among the online journalists interviewed, the relevance of SEO lies in the fact that SEO is regarded as a standard practice that should at least be kept in mind when writing copy for the web. Employers and clients also increasingly require this knowledge from journalists. However, concerns were also expressed that SEO could have a negative impact on the quality of writing should journalistic quality criteria become less important than SEO techniques. This fear is in line with statements made in previous interviews on SEO in the journalistic context (Giomelakis et al., 2019; Prawira and Rizkiansyah, 2018). Thus, without being able to clearly quantify SEO's influence on rankings, SEO is considered a highly relevant topic for all three interview groups. In particular, the need for content managers (e.g., portal managers or chief editors) to increase the visibility of their content and the business interests of search engine optimizers led to large dependencies between the two groups.

Despite the topic's relevance, the respondents did not assume that search engine users were familiar with SEO. With one exception, all interviewees stated that users probably do not know SEO or how SEO works. Not surprisingly, it is also assumed that users do not have an accurate concept of how strong SEO's influence on rankings actually is. The limited user knowledge could lead to misjudgements such as equating SEO with spamming, resulting in users developing a negative attitude towards SEO. Interestingly, these expectations were also shared by the search engine optimizers. At this point, a clear contrast emerges. On the one hand, there are search engine optimizers who have a consistently positive image of their work and perceive it as a service to the user. On the other hand, there are the users who are not expected to have any knowledge of SEO, nor a consistently positive opinion of SEO.

These findings clearly show the need to include user perspectives in the analysis. Should the assumptions regarding user knowledge of and opinions on SEO be confirmed by the representative online survey to be carried out by the SEO Effect project, this finding would be in line with previous studies which revealed low information literacy among search engine users (e.g., Lewandowski et al., 2018; Singer et al., 2012; Stark et al., 2014). Furthermore, it can then be determined to what extent the user's perspective on SEO actually depends on their knowledge of SEO, and whether more informed users view SEO in a more positive light.

The industry in which the user is active, the educational level of the user, and the personal interests he or she has were considered to be crucial for their perspectives on SEO. If the industry or the profession of the user overlaps with SEO topics, a higher level of knowledge and thus a more positive opinion about SEO can be assumed. SEO knowledge was also considered to be higher among those 
users who have a high level of education or a private (non-professional) interest in search engines. However, the assumption that younger users (so-called 'digital natives') had a higher level of knowledge about SEO than older users was supported by as many experts as it was rejected. From the point of view of the experts who don't see age as an influencing factor, the contact to search engines would not go beyond their use, even for young users.

\section{Conclusion}

In this article, we aimed to describe the role of search engine optimization (SEO) in the interaction of stakeholders responsible for creating content and making it visible. For this purpose, we conducted expert interviews with search engine optimizers, content managers, and online journalists. The interviews are part of the SEO Effect project, which seeks to describe and explain the role of SEO from the perspectives of the participating stakeholder groups.

The respondents emphasized the great importance of SEO when it comes to making content visible through search engines. The interviewees also provided us with their assessments of search engine user perspectives on SEO. From these assumptions, hypotheses were derived for a representative online survey, which represents the next step of our project. Central hypotheses are that search engine users know little about the influence of SEO on search results, have distorted perceptions regarding the impact of SEO (too high/too low), and that their perspective on SEO depends on demographic factors such as level of education and profession. The online survey on user perspectives, a topic that has yet to be researched, is of particular importance for assessing the information literacy of search engine users.

Future studies should address the issues revealed in the course of the interviews. The influence of SEO on journalistic practices is one aspect worthy of further examination. The results also indicate a need to strengthen the information literacy of users in terms of the actors involved in the ranking.

\section{Research data}

All research data (transcripts, declaration of consent, MAXQDA file) are available at: https://doi.org/10.17605/OSF.IO/JYV9R.

\section{Acknowledgements}

The authors would like to thank Daniela Sygulla for her help in coding the interviews.

\section{Funding}

This work is funded by the German Research Foundation (DFG - Deutsche Forschungsgemeinschaft), [grant number 417552432].

\section{References}

Akram, M., Sohail, I., Hayat, S., Shafi, M.I. and Saeed, U. (2010), "Search Engine Optimization Techniques Practiced in Organizations: A Study of Four Organizations”, Journal of Computing, Vol. 2 No. 6, pp. 134-139. 
Alphabet Inc. (2017), “Annual Report Pursuant to Section 13 or 15(d) of the Securities Exchange Act of 1934 for the Fiscal Year Ended December 31, 2016", available at: https://abc.xyz/investor/static/pdf/20161231_alphabet_10K.pdf (accessed 20 June 2020).

Alphabet Inc. (2019), “Alphabet Announces Fourth Quarter and Fiscal Year 2018 Results”, available at: https://abc.xyz/investor/static/pdf/2018Q4_alphabet_earnings_release.pdf(accessed 15 June 2019).

Beel, J., Gipp, B. and Wilde, E. (2010), “Academic Search Engine Optimization (ASEO): optimizing Scholarly Literature for Google Scholar and Co.”, Journal of Scholarly Publishing, Vol. 41 No. 2, pp. 176-190, DOI: 10.3138/jsp.41.2.176.

Clarke, A. (2019), SEO 2020: learn Search Engine Optimization With Smart Internet Marketing Strategies.

Van Couvering, E. (2007), "Is Relevance Relevant? Market, Science, and War: discourses of Search Engine Quality”, Journal of Computer-Mediated Communication, Vol. 12 No. 3, pp. 866-887, DOI: 10.1111/j.1083-6101.2007.00354.x.

Van Couvering, E. (2009), "Search Engine Bias: the Structuration of Traffic on the World-Wide Web", available at: http://etheses.lse.ac.uk/41/ (accessed 17 May 2020).

Dick, M. (2011), "Search engine optimisation in UK news production", Journalism Practice, Vol. 5 No. 4, pp. 462-477, DOI: 10.1080/17512786.2010.551020.

Erlhofer, S. (2018), Suchmaschinen-Optimierung: das Umfassende Handbuch, 9. ed., Rheinwerk Verlag, Bonn.

European Commission. (2017), “Antitrust: Commission fines Google $€ 2.42$ billion for abusing dominance as search engine by giving illegal advantage to own comparison shopping serviceFactsheet", available at: http://g8fip1kplyr33r3krz5b97d1.wpengine.netdna-cdn.com/wpcontent/uploads/2017/06/Google-MEMO-17-1785_EN.pdf (accessed 1 August 2018).

Giomelakis, D., Karypidou, C. and Veglis, A. (2019), "SEO inside Newsrooms: reports from the Field", Future Internet, Vol. 11 No. 12, DOI: 10.3390/fi11120261.

Giomelakis, D. and Veglis, A. (2016), "Investigating Search Engine Optimization Factors in Media Websites", Digital Journalism, Vol. 4 No. 3, pp. 379-400, DOI: 10.1080/21670811.2015.1046992.

Google.com. (2020), "Google - info”, available at: https://about.google/ (accessed 21 April 2020).

Grimmelmann, J. (2010), "Some skepticism about search neutrality", Szoka, B. and Marcus, A. (Ed.s), The next Digital Decade: essays on the Future of the Internet, TechFreedom, Washington, DC, pp. 435-459.

Jansen, B.J. and Molina, P.R. (2006), "The effectiveness of Web search engines for retrieving relevant ecommerce links", Information Processing \& Management, Vol. 42 No. 4, pp. 1075-1098, DOI: 10.1016/j.ipm.2005.09.003.

Kai Li, Mei Lin, Zhangxi Lin and Bo Xing. (2014), "Running and Chasing - the Competition between Paid Search Marketing and Search Engine Optimization”, in Sprague, R.H. (Ed.), Proceedings of the 47th Annual Hawaii International Conference on System Sciences, Waikoloa, Hawaii, pp. 3110-3119, DOI: 10.1109/HICSS.2014.640.

Latour, B. (1990), "Technology is Society Made Durable”, The Sociological Review, Vol. 38 No. 1_suppl, pp. 103-131, DOI: 10.1111/j.1467-954X.1990.tb03350.x.

Latour, B. (2005), Reassembling the Social: an Introduction to Actor-Network-Theory, Oxford University Press, Oxford.

Lewandowski, D. (2017), “Is Google Responsible for Providing Fair and Unbiased Results?”, Taddeo, M. and Floridi, L. (Ed.s), The Responsibilities of Online Service Providers, Springer, Berlin, pp. 61-77, DOI: 10.1007/978-3-319-47852-4_4.

Lewandowski, D., Kerkmann, F., Rümmele, S. and Sünkler, S. (2018), “An empirical investigation on search engine ad disclosure", Journal of the Association for Information Science and Technology, Vol. 69 No. 3, pp. 420-437, DOI: 10.1002/asi.23963.

Lopezosa, C., Codina, L. and Pérez-Montoro, M. (2019), "SEO and Digital News Media: visibility of Cultural Information in Spain's Leading Newspapers”, Trípodos, No. 44, pp. 41-61.

Machill, M., Beiler, M. and Zenker, M. (2008), "Search-engine research: a European-American 
overview and systematization of an interdisciplinary and international research field", Media, Culture \& Society, Vol. 30 No. 5, pp. 591-608, DOI: 10.1177/0163443708094010.

Mager, A. (2012), "Algorithmic Ideology: how capitalist society shapes search engines", Information, Communication \& Society, Vol. 15 No. 5, pp. 769-787, DOI: 10.1080/1369118X.2012.676056.

Mager, A. (2018), "Internet governance as joint effort: (re)ordering search engines at the intersection of global and local cultures", New Media \& Society, Vol. 20 No. 10, pp. 3657-3677, DOI: $10.1177 / 1461444818757204$.

McCue, T. (2018), "SEO Industry Approaching \$80 Billion But All You Want Is More Web Traffic", available at: https://www.forbes.com/sites/tjmccue/2018/07/30/seo-industry-approaching-80billion-but-all-you-want-is-more-web-traffic/ (accessed 1 October 2019).

Moz.com. (2015), "Ranking Correlation Study 2015 - Moz", available at: https://moz.com/searchranking-factors/correlations (accessed 11 October 2019).

Moz.com. (2020), "Moz - SEO Software, Tools \& Resources for Smarter Marketing", available at: https://moz.com/ (accessed 16 January 2020).

Neethling, R. (2007), "Search Engine Optimisation or Paid Placement Systems - user Preference", available at: http://etd.cput.ac.za/handle/20.500.11838/1359 (accessed 7 May 2019).

Niranjika, U. and Samarasighe, D. (2019), "Exploring the Effectiveness of Search Engine Optimization Tactics for Dynamic Websites in Sri Lanka", in Book of conference proceedings: 5th International Multidisciplinary Engineering Research Conference, University of Moratuwa, Katubedda, Sri Lanka, pp. 267-272, DOI: 10.1109/MERCon.2019.8818903.

Pan, B., Hembrooke, H., Joachims, T., Lorigo, L., Gay, G. and Granka, L. (2007), "In Google We Trust: users' Decisions on Rank, Position, and Relevance", Journal of Computer-Mediated Communication, Wiley Online Library, Vol. 12 No. 3, pp. 801-823, DOI: 10.1111/j.10836101.2007.00351.x.

Prawira, I. and Rizkiansyah, M. (2018), "Search engine optimization in news production online marketing practice in Indonesia online news media", Pertanika Journal of Social Sciences and Humanities, Vol. 26 No. T, pp. 263-270.

Purcell, K., Brenner, J. and Rainie, L. (2012), "Search Engine Use 2012", available at: https://www.eff.org/files/pew_2012_0.pdf (accessed 14 April 2018).

Rashid, J., Adnan, S.M., Nisar, M.W.W., Irtaza, A., Arafat, S.Y. and Iqbal, M.J. (2018), “Advertiser's perception of Internet marketing for small and medium enterprises in Pakistan", in 2018 International Conference on Computing, Mathematics and Engineering Technologies: Invent, Innovate and Integrate for Socioeconomic Development, ICoMET 2018 - Proceedings, pp. 17, DOI: 10.1109/ICOMET.2018.8346362.

Richards, K.A.R. and Hemphill, M.A. (2018), "A Practical Guide to Collaborative Qualitative Data Analysis", Journal of Teaching in Physical Education, Vol. 37 No. 2, pp. 225-231, DOI: 10.1123/jtpe.2017-0084.

Rieder, B. (2005), "Networked control: search engines and the symmetry of confidence", International Review of Information Ethics, Vol. 3 No. 1, pp. 26-32.

Röhle, T. (2010), Der Google-Komplex: über Macht Im Zeitalter Des Internets, Transcript, Bielefeld, Germany.

Schultheiß, S., Sünkler, S. and Lewandowski, D. (2018), "We still trust in Google, but less than 10 years ago: an eye-tracking study", Information Research, Vol. 23 No. 3, paper 799.

searchengineland.com. (2020), "SEO - search engine optimization news \& trends | Search Engine Land", available at: https://searchengineland.com/library/channel/seo (accessed 16 January 2020).

Sheffield, J.P. (2020), "Search Engine Optimization and Business Communication Instruction: Interviews With Experts", Business and Professional Communication Quarterly, pp. 153-183, DOI: $10.1177 / 2329490619890335$.

Similarweb.com. (2020), "SimilarWeb | Website Traffic Statistics \& Market Intelligence", available at: https://www.similarweb.com/ (accessed 15 March 2020).

Singer, G., Norbisrath, U. and Lewandowski, D. (2012), "Ordinary Search Engine Users assessing Difficulty, Effort, and Outcome for Simple and Complex Search Tasks", in Kamps, J., Kraaij, 
W. and Fuhr, N. (Ed.s), Proceedings of the Fourth Information Interaction in Context Symposium, Nijmegen, Netherlands, pp. 110-119, DOI: 10.1145/2362724.2362746.

Stark, B., Magin, M. and Jürgens, P. (2014), "Navigieren im Netz: Befunde einer qualitativen und quantitativen Nutzerbefragung", Stark, B., Dörr, D. and Aufenanger, S. (Ed.s), Die Googleisierung Der Informationssuche, De Gruyter, Berlin, Boston, pp. 20-74.

StatCounter. (2019), "Search Engine Market Share United States Of America | StatCounter Global Stats", available at: http://gs.statcounter.com/search-engine-market-share/all/united-states-ofamerica (accessed 2 July 2019).

StatCounter. (2020), "Search Engine Market Share Europe | StatCounter Global Stats", available at: https://gs.statcounter.com/search-engine-market-share/all/europe (accessed 5 March 2020).

Tavani, H.T. (2012), "Search Engines and Ethics", Stanford Encyclopedia of Philosophy, pp. 1-23.

Varian, H. (2006), "The Economics of Internet Search", Rivista Di Politica Economica, Vol. 96 No. 6, pp. 9-23.

Westerwick, A. (2013), "Effects of Sponsorship, Web Site Design, and Google Ranking on the Credibility of Online Information", Journal of Computer-Mediated Communication, Vol. 18 No. 2, pp. 194-211, DOI: 10.1111/jcc4.12006.

Zhang, L., Zhang, J. and Ju, Y. (2011), "The research on Search Engine Optimization based on Six Sigma Management", in 2011 International Conference on E-Business and E-Government (ICEE), Shanghai, China, pp. 1-4, DOI: 10.1109/ICEBEG.2011.5881880.

Zhang, Y. and Wildemuth, B.M. (2009), "Qualitative Analysis of Content", in Wildemuth, B.M. (Ed.), Applications of Social Research Methods to Questions in Information and Library Science, Libraries Unlimited, Westport, Conn, pp. 318-329.

Ziakis, C., Vlachopoulou, M., Kyrkoudis, T. and Karagkiozidou, M. (2019), "Important Factors for Improving Google Search Rank", Future Internet, Vol. 11 No. 32, DOI: 10.3390/fi1102003.

Ziewitz, M. (2019), "Rethinking gaming: the ethical work of optimization in web search engines", Social Studies of Science, Vol. 49 No. 5, pp. 707-731, DOI: 10.1177/0306312719865607.

Zuze, H. and Weideman, M. (2013), "Keyword stuffing and the big three search engines", Online Information Review, Vol. 37 No. 2, pp. 268-286, DOI: 10.1108/OIR-11-2011-0193.

\section{Appendix 1}

Table III: Coding scheme

\begin{tabular}{|c|c|}
\hline Code & Description \\
\hline \multicolumn{2}{|c|}{ Information about the interview partner (IP) } \\
\hline IP_Points of contact & $\begin{array}{l}\text { Points of contact in everyday business with SEO (only content managers and } \\
\text { online journalists) }\end{array}$ \\
\hline IP Experience & Experience in the SEO field (group of search engine optimizers only) \\
\hline IP_Motivation & Motivation to work in the SEO field (group of search engine optimizers only) \\
\hline IP Role & Role in company/professional role \\
\hline \multicolumn{2}{|c|}{ Users' perspectives regarding SEO (UP) } \\
\hline UP_Assessment weak & Users' assessment of the SEO influence rated as weak \\
\hline UP Assessment moderate & Users' assessment of the SEO influence rated as moderate \\
\hline UP Assessment strong & Users' assessment of the SEO influence rated as strong \\
\hline UP_Factor age & $\begin{array}{l}\text { Expected differences in the users' perspectives on SEO regarding the users' } \\
\text { age }\end{array}$ \\
\hline UP_Factor education & $\begin{array}{l}\text { Expected differences in the users' perspectives on SEO regarding the users' } \\
\text { education }\end{array}$ \\
\hline UP_Factor industry & $\begin{array}{l}\text { Expected differences in the users' perspectives on SEO regarding the industry } \\
\text { in which the user works }\end{array}$ \\
\hline UP_Factor personal interests & $\begin{array}{l}\text { Expected differences in the users' perspectives on SEO regarding the users' } \\
\text { personal interests }\end{array}$ \\
\hline UP_Factor experience & $\begin{array}{l}\text { Expected differences in the users' perspectives on SEO regarding the users' } \\
\text { professional experiences }\end{array}$ \\
\hline
\end{tabular}




\begin{tabular}{|c|c|}
\hline UP_Factor general & $\begin{array}{l}\text { General aspects on differences between users, for example that generally no } \\
\text { differences in the users' perspectives on SEO are assumed }\end{array}$ \\
\hline UP Knowledge low & Users' knowledge of SEO rated as low \\
\hline UP_Knowledge average & Users' knowledge of SEO rated as average \\
\hline UP Knowledge high & Users' knowledge of SEO rated as high \\
\hline UP Opinion negative & Users' opinion of SEO rated as negative \\
\hline UP Opinion positive & Users' opinion of SEO rated as positive \\
\hline UP_Opinion divided & $\begin{array}{l}\text { Users' opinion of SEO rated as divided, e.g., if it depends on the individual } \\
\text { case }\end{array}$ \\
\hline UP_personally differentiated & $\begin{array}{l}\text { Interviewees rate the impact of SEO from their personal perspective as } \\
\text { differentiated, e.g., that the SEO influence depends on the individual } \\
\text { case/website }\end{array}$ \\
\hline UP personally strong & Interviewees rate the impact of SEO as strong from their personal perspective \\
\hline \multicolumn{2}{|c|}{$\begin{array}{l}\text { Role and influence of SEO on everyday work (RAI; groups of content managers/online journalists } \\
\text { only) }\end{array}$} \\
\hline RAI_Importance low & Current importance of SEO in everyday working life is low \\
\hline RAI_Importance average & Current importance of SEO in everyday working life is average \\
\hline RAI Importance high & Current importance of SEO in everyday working life is high \\
\hline RAI_Changes small & $\begin{array}{l}\text { Minor expected changes in the relationship between SEO and content } \\
\text { managers/online journalists }\end{array}$ \\
\hline RAI_Changes moderate & $\begin{array}{l}\text { Average expected changes in the relationship between SEO and content } \\
\text { managers/online journalists }\end{array}$ \\
\hline RAI_Changes big & $\begin{array}{l}\text { Significant expected changes in the relationship between SEO and content } \\
\text { managers/online journalists }\end{array}$ \\
\hline
\end{tabular}

${ }^{[1]}$ https://searchstudies.org/seo-effekt/

${ }^{[2]}$ https://www.olympus.de/site/de/archived_products/audio/audio recording 1/ls _11/index.pdf

${ }^{[3]}$ https://www.maxqda.com/products/maxqda-standard 